\title{
A nálise do processo de trabalho em laboratórios de pesquisa em saúde: uma proposta de investigação
}

\author{
Analysis of the work process in health research \\ laboratories: a proposal for investigation
}

Márcia de Oliveira Teixeira 1

\footnotetext{
1 Departamento de Formação Profissional em Ciência e Tecnologia em Saúde, Escola Politécnica de Saúde Joaquim Venâncio, Fundação Oswaldo Cruz. Av. Brasil 4365 Rio de Janeiro, RJ 21045-900, Brasil.
}

Abstract This article presents a proposal for analyzing the work process involved in building technoscientific knowledge in the health field, focusing on the work developed by research laboratory technicians in the Oswaldo Cruz Foundation. Beginning with an in-depth description of the technicians' laboratory activities, we discuss the relationship between the various stages of work and the different actors, the technicians' value as actors in the process of building knowledge, and various actors' perceptions of how essential this work is. We attempt to outline the context in which the work processes in health sciences laboratories were incorporated into an analysis of the work process in health. By establishing a dialogue with the sociology of science, we present our proposal as an attempt to introduce new social sciences approaches for analyzing the work process, specifically as applicable to an analysis of work in the health field.

Key words Laboratory Personnel; Laboratories; Technology in Health; Health Manpower

Resumo Este artigo apresenta uma proposta de análi se dos processos de trabal ho envolvidos na construção de conhecimentos tecnocientíficos no campo da saúde, concentrando-se no trabalho desenvolvido pelos técni cos de nível médio, em laboratórios de unidades de pesquisa da Fundação Oswal do Cruz. Partindo de uma descrição densa das atividades desenvolvidas no interior destes laboratórios por tais técnicos, discutimos: as interações entre as várias etapas do trabal ho e seus diferentes atores, a valorização dos técni cos enquanto atores do processo de construção de conhecimentos, bem como a percepção de sua essenciali dade pel os di ferentes atores. Como etapa fundamental da discussão desta proposta, procuraremos delinear a conjuntura na qual os processos de trabal ho em laboratórios de ciência e tecnol ogia em saúde foram incorporados à analise dos processos de trabal ho em saúde. Em seguida, a partir do estabel ecimento de um intenso diálogo com as proposições da sociologia da ciência, situaremos nossa proposta como uma tentativa de incorporar novas abordagens do campo das ciências sociais à análi ise do processo de trabalho. Ao fazêlo, colocamos como uma de nossas principais questões a possi bilidade deste instrumental adequar-sea uma análise, cujo eixo éo processo de trabal ho em saúde. Palavras-chave Pessoal de Laboratório; Laboratórios; Tecnologia em Saúde; Recursos Humanos em Saúde 


\section{Introdução}

Este artigo tem como principal objetivo a discussão de uma proposta de análise do processo de trabalho de técnicos de nível médio em laboratórios de C\&T em saúde, que vem sendo desenvolvida pela Escola Politécnica de Saúde Joaquim Venâncio EPSJV/Fiocruz (Teixeira, 1994). Nossa discussão parte da impossibilidade de compreensão do processo de trabalho dos técnicos de nível médio, nos laboratórios de pesquisa e desenvolvimento (P\&D) da Fundação Oswaldo Cruz, dissociada da inteligibilidade do próprio processo de construção dos conhecimentos tecnocientíficos. Procuramos, por conseguinte, incorporar à análise dos processos de trabal ho em saúde um instrumental teórico metodológico voltado à compreensão dos processos de construção dos saberes tecnocientíficos, sua legitimação e difusão pela sociedade. Deste modo, colocamos como uma de nossas principais questões a possibilidade de este instrumental se adequar a uma análise cujo eixo é o processo de trabalho em saúde.

\section{A invisibilidade do trabalho técnico e as análises do processo de trabalho em saúde}

A trajetória da temática dos recursos humanos em saúde, à qual a análise dos processos de trabalho está articulada, confunde-se com o próprio movimento de aproximação e interação entre as ciências sociais e as ciências biomédicas (Mercer, 1985; Nunes 1985a e b). Ao longo das três últimas décadas, esta temática foi marcada pela introdução de novos referenciais teóricos e metodológicos, resultando na utilização progressiva das categorias de força de trabal ho, profissões em saúde, e mais recentemente de processos de trabal hos em saúde. As metamorfoses sofridas por essa temática, além de traduzirem transformações no interior do campo da saúde, acompanham a dinâmica das ciências sociais, que se deslocam em direção à síntese teórica entre a ação e a estrutura, após duas décadas de profunda polarização, opondo as escolas de macroteorização, de viés estruturalista, às de microteorização, sendo, entretanto, identificadas às propostas fenomenológicas (Alexandrer, 1987). Deste modo, é possível inserirmos as categorias de força de trabalho e profissões em saúde no interior deste movimento pendular, entre a estrutura e a ação: enquanto a força de trabalho evoca um “agente subordinado à organização social da produção e distribui ção dos serviços" (Schrai- ber \& Peduzzi, 1992:15-16), a categoria de profissões em saúde nos remete à noção de sujeitos plenos da ação (op.cit). No campo da saúde, esse movimento de síntese manifesta-se pela crescente utilização da categoria de processos de trabalho em saúde e pela retomada da categoria de recursos humanos em saúde (Gonçalves, 1992).

De modo geral, o conjunto destas análises, referenciadas por diferentes abordagens do campo das ciências sociais, guarda algumas similitudes entre si, das quais destacamos o fato de prenderem-se quase que exclusivamente aos profissionais de nível superior, com nítido privilégio dos médicos, e aos serviços de saúde. Nos últimos anos, como parte da tendência de discutir as práticas de saúde cotidianamente realizadas dentro de postos de saúde e hospitais, outros profissionais lentamente foram incorporados à análise, contudo ainda carecemos de um olhar mais minucioso sobre os quadros de nível médio. Além disso, se o universo de técnicos de laboratório e auxiliares dos serviços de saúde ainda permanece em parte desconhecido, quando nos voltamos para os técnicos vinculados aos laboratórios de C\&T em saúde, passamos a navegar por um terreno ainda inexplorado. As análises dos diferentes processos de trabalho em saúde continuam, em sua maior parte, presas ao setor de serviços de saúde, apesar do fortalecimento do papel das instituições de pesquisa e desenvolvimento no setor saúde.

Todavia, a invisibilidade dos técnicos não está restrita, ou não é um fenômeno restrito, aos programas de pesquisa que analisam as tecnociências e os processos de trabalho em saúde. Apesar de participarem ativamente do trabalho experimental, estando encarregados de toda a sua fase preparatória, tais profissionais não são mencionados em artigos e relatórios. Por conseguinte, aqueles que possuem uma atuação fundamental no conjunto de atividades, as quais inauguram e distinguem as ciências modernas de outras formas de conhecimentos (os procedimentos experimentais), são invisíveis quando repensamos essa forma de construção de conhecimentos tecnocientíficos. A origem dessa invisibilidade não reside apenas na hierarquização da divisão social do trabal ho, a qual privilegia o trabalho intelectual, uma vez que os técnicos estão relacionados, historicamente, com o desenvolvimento de funções essencialmente manuais, para as quais bastaria o domínio de alguns poucos conhecimentos práticos e habilidades. Esta linha explicativa é correta, porém limitada. Compreenderemos a invisibilidade, em toda sua extensão, ao aliarmos a argumentação anterior à 
concepção individualista das ciências, que nega sua dimensão de construção coletiva:

“Essa é mais uma interpretação que faz da descoberta ci entífica uma espécie de revel ação, um brevelampejo do gênio individual, em contraste com os esforços prol ongados de um trabaIho col etivo. Defato, as numerosas anedotas nos fazem pensar que mesmo hoje, à época da "big science", essa concepção individualista da ciência como revelação está presente. Ela constitui a base cultural que explica a invisibilidade dos técni cos e de outras categorias profissionais associadas à pesquisa científica, daí advém nossa tendência de ver a ciência como uma atividade puramente intel ectual mais do que como um trabalho" (Shapin, 1991:330).

Podemos redesenhar uma série de contextos, que, articulados, possibilitarão a 'fertilização' da problematização dos processos de trabalho em instituições de pesquisa e desenvolvimento no campo da saúde. Destacamos a elaboração e implementação do Plano de Carreira de Ciência e Tecnologia, o qual, ao estimular a reconfiguração de algumas carreiras, terminou por tornar patente o desconhecimento de alguns processos de trabalhos aí incluídos. Este desconhecimento reaparece, constituindo-se como segundo fator, quando se discute a capacitação dos profissionais de nível médio das instituições de C\&T em saúde, pois a análise das deficiências e a seleção das possíveis disciplinas oferecidas esbarram continuamente na carência de informações sobre as atividades cotidianas desenvolvidas por esses profissionais, sobretudo porque os vários processos de trabalho de um determinado laboratório, apesar de guardarem diferenças entre si, são interdependentes e de difícil compreensão quando fragmentados.

Nas análises voltadas à investigação dos processos de trabal ho no setor de serviços de saúde, a identificação do desconhecimento das atividades realizadas, principalmente pelos trabalhadores de nível médio, aliada à necessidade de resgatar as condições sociais de realização dos diferentes processo de trabal ho em saúde resultaram em um movimento de fortalecimento do instrumental metodológico clássico da antropologia, no interior do campo da saúde. Nos últimos anos, discernimos um aumento no número de dissertações voltadas à investigação da dinâmica assumida pelo trabaIho nos serviços de saúde, bem como as mudanças trazidas pela introdução de novas tecnologias, apoiadas na reconstrução da história de vida, na observação minuciosa das atividades cotidianas e na análise de discurso (Schraiber, 1993; Gonçalves, 1994).
Como terceiro ponto, sublinhamos os questionamentos em torno das relações entre as tecnociências e a sociedade, traduzidos na rápida disseminação dos Estudos de Laboratório no País, a partir da década de 80, que estabelecem uma rica e intensa interlocução com a etnometodologia, compartilhando problemáticas e categorias de análise, às quais retornaremos mais adiante, pois, antes de explicitarmos quais características distinguem os Estudos de Laboratório, é necessário expor o referencial teórico-metodológico sobre o qual eles estão assentados.

\section{Uma abordagem sociológica das tecnociências}

As últimas décadas assistiram à rápida disseminação de uma nova representação social das tecnociências, na qual estas são traduzidas como um modo particular de construir enunciados reorganizando o mundo, exercício que não pode ser desconectado do contexto social no qual esta construção é efetuada. As tecnociências não constituem um campo soberano, regulado por normas geradas no interior da comunidade científica, não dialogam simplesmente com a sociedade, estão, pelo contrário, mergulhadas nos impasses políticos, econômicos e jurídicos que as permeiam. De certo modo, expressões como dialogar e ligar são impróprias, ao reafirmarem a existência de instâncias autônomas, uma vez que estamos tratando de campos cuja existência enquanto tais se pauta na mistura, no laço apertado e indissociável, na interdependência. É possível precisarmos com rigor em qual momento a pesquisa atômica perde sua 'pureza', sua qualidade de essencial e eminentemente científica, 'enrolando-se' com a política e a economia? E a Aids, pode ser efetivamente enclausurada como uma questão científica e de saúde? O descomunal impulso em suas pesquisas só pode ser compreendido caso ampliemos nosso campo de análise; incluiríamos, então, o poder político e econômico da comunidade gay, a disputa dos grandes conglomerados farmacêuticos envolvendo mercados, as polêmicas em torno do comportamento sexual nas últimas décadas e o preconceito.

Gradualmente, portanto, assistimos ao crescimento de propostas cujas análises não estão concentradas na identificação das tecnociências apenas como um corpo teórico-cognitivo, extremamente complexo; passam a privilegiar seu caráter de prática social, simultaneamente política, econômica e cultural. 
Entretanto, reconhecer a unicidade dos laços e fios, que atam em uma espécie de tecido sem costura as tecnociências, a política, a economia e todos os campos abrigados sobre a égide do social, não basta, caso a meta seja tornar esta malha única inteligível. Repetimos com certa contumácia que as tecnociências são construídas socialmente, mas de fato o que isso significa? Como essa articulação densa manifesta-se cotidianamente nas bancadas, nas salas de reunião e em toda sorte de eventos tecnocientíficos? De que modo as ciências sociais, e em especial a sociologia, poderiam investigar as tecnociências como práticas sociais? (Latour, 1989)

Um novo caminho foi aberto, no final da década de 60, por um grupo multidisciplinar da Universidade de Edimburgo, constituído por lingüistas, filósofos, sociólogos e matemáticos, unidos pela inquietação diante das proposições sociológicas e filosóficas na abordagem das tecnociências. Recolhendo influências de um amplo leque de autores e disciplinas, tomaram como ponto de partida a noção de construção social dos conhecimentos tecnocientíficos, defendendo ardorosamente a necessidade de se incorporar o conteúdo das pesquisas ao campo de análise. Esse princípio pode ser apontado como instaurador do Programa Forte em Sociologia do Conhecimento, cujas problemáticas centrais circulam ao redor basicamente de dois pontos (Bloor, 1976):

a) a ruptura com a noção de que as tecnociências, a política, a economia, o direito, constituem esferas atomizadas, podendo, portanto, ser compreendidas separadamente;

b) a estreita inter-relação entre estes campos está traduzida no conteúdo dos enunciados tecnocientíficos, os quais se tornam parte da análise sociológica das práticas científicas.

A sociologia não deveria limitar-se a interrogar como o social influencia os resultados das pesquisas, passando a compreendê-los como fruto de um contexto constituído pela interseção de múltiplas dimensões, simultaneamente transformando-as e sendo transformado por elas.

As proposições do Programa Forte misturadas com outras abordagens, também marcadas pelo caráter multidisciplinar, deram origem a uma série de estudos, conformando um campo de análise - campo dos Estudos Sociais das Ciências e das Técnicas -, cuja unicidade reside na perspectiva de identificar a tessitura social nos próprios conteúdos das pesquisas tecnocientíficas. Dentro deste intenso movimento de transformação das abordagens sociológicas das tecnociências, um grupo distingue-se pela incorporação de instrumentais etnográficos para analisar as práticas realizadas nos laboratórios, fundando a corrente de Estudos de Laboratório. A microanálise das práticas cotidianas é defendida como único modo de compreender a complexidade das atividades científicas (Latour \& Woolgar, 1988). A Sociologia das Ciências (Sociologia da Inovação, para Michel Callon, ou das Associações, como prefere Bruno Latour), e em especial os Estudos de Laboratório, partem da oposição a outras abordagens, que circulam pelo campo dos Estudos Sociais das Ciências e das Técnicas, para tornar as relações entre as tecnociências e a sociedade mais compreensíveis. Essas críticas podem ser aglutinadas em três pontos básicos:

a) De modo geral, ao posicionarem-se fora dos laboratórios, estas abordagens terminaram excluindo de seu campo de análise o conteúdo em si das pesquisas. A interseção entre as ciências, as técnicas e o social é apreendida da análise do discurso dos pesquisadores, das comunicações formais e informais, da produção de textos científicos, debates em torno da ética científica, dos fóruns de divulgação e interface com grupos de pressão não científicos. A análise parte de fatos prontos, não problematizando as condições de sua produção, atendo-se mais à difusão dos conhecimentos na sociedade.

b) Ao promoverem uma crítica contundente ao centralismo das abordagens economicistas e cientificistas, alguns estudos terminam supervalorizando a dimensão social, desconsiderando completamente os fatores essencialmente científicos, os quais também condicionam as pesquisas.

c) A conseqüência direta deste modo de recortar o campo de análise é a reificação da independência das tecnociências, reafirmando que as decisões respaldam-se no julgamento puramente científico. Corre-se o risco, portanto, de desconectarem-se mais uma vez as ciências, as técnicas e o social. A comunidade científica adquire grande autonomia como instância reguladora/ legitimadora, mediando as relações entre os pesquisadores, suas escolhas e as demandas sociais expressas por diferentes grupos.

Nesta perspectiva, o laboratório, espaço até então não profanado, é 're-significado' como local de interseção de inúmeros atores heterogêneos - pesquisadores, economistas, burocratas, parlamentares, industriais, jornalistas -, os quais, movidos por interesses diversos, influenciam em maior ou menor grau as escolhas e decisões antes consideradas como essencialmente técnicas. A compreensão das práticas tecnocientíficas é refém da capacidade de abrir 
a dinâmica de suas relações, uma vez que os fatos/ artefatos tecnocientíficos caracterizam-se por não serem de ordem eminentemente natural e nem inteiramente social, são elementos híbridos, definidos como uma configuração assumida por uma associação de atores e campos interdependentes (social/tecnocientífico). Os sociólogos identificados com essa proposta teórico-metodológica procuram compreender a dinâmica dessa associação (Latour, 1994), na qual diferentes atores geram áreas de influência - campos de força - capazes de fortalecer o laboratório dentro de seu campo disciplinar, direcionando decisões internas e externas, favorecendo a transferência de conhecimentos localmente construídos para a sociedade. Ao declararmos que os conhecimentos tecnocientíficos são socialmente construídos, estamos afirmando que esses conhecimentos são gestados ao longo e segundo a intensidade do embate de forças sociais e tecnocientíficas, manobradas e reunidas pelos pesquisadores, no interior dos laboratórios. Interpretamos os conhecimentos tecnocientíficos como produtos de um conjunto de ações al tamente políticas, acarretando, como coloca Lévy (1993), a identificação dos pesquisadores enquanto homens políticos, preocupados simultaneamente com processos eminentemente sociais e com a "engrenagem complicada das coisas"(Lévy, 1993: 55).

\section{Os estudos de laboratório}

Concentrar-nos-emos nos Estudos de Laboratório, com o intuito de localizá-los no interior das proposições teórico-metodológicas da Sociologia da Ciência, explicitando sua especificidade, bem como a de nossa própria proposta. Sua interpretação do processo de 'produção' dos conhecimentos tecnocientíficos, geralmente chamada de 'construtivista', apóia-se na impossibilidade de se realizar uma investigação dos conhecimentos produzidos dissociada da inteligibilidade das práticas que os constituíram.

Quando abandonaram as explicações concentradas na análise de produtos já prontos, defendendo a incorporação da discussão dos conteúdos das pesquisas realizadas nos laboratórios, os sociólogos buscaram reconstruir o processo de pesquisa, ao longo do qual encontraremos apenas enunciados frágeis e cambiantes. A investigação se concentra nos laboratórios, espaço de produção de fatos e relações sociais, representados como um campo conflitual, onde diferentes forças oriundas de diversas áreas (políticas, econômicas, jurídicas) interagem cotidianamente. A viabilização desta proposta recai na escolha de instrumentais que assegurem o acesso aos microeventos, os quais conformam o contexto social de construção de um determinado conhecimento ou artefato tecnocientífico. Os Estudos de Laboratório traduzem a opção por uma análise densa do cotidiano dos laboratórios de pesquisa, amplamente influenciada pelo instrumental clássico da antropologia. A observação e o registro minuciosos das atitudes e práticas, executadas pelo conjunto de trabalhadores envolvidos nas atividades de pesquisa, são aliadas às técnicas de análise de discurso e à recomposição das trajetórias individuais, por meio dos relatos e da análise documental, para a reconstituição do processo de construção dos conhecimentos tecnocientíficos. Os sociólogos esperam identificar as situações contingenciais, os interesses e disputas, que influenciam as decisões tomadas pelos pesquisadores ao longo do processo de construção dos conhecimentos tecnocientíficos, posteriormente justificadas como sendo cientificamente adequadas.

Os autores identificados com os Estudos de Laboratório promovem uma instigante e inusitada etnografia dos laboratórios, baseada nos estudos de culturas não ocidentais e de grupos urbanos e rurais, empregando a análise de discurso com suas diferentes escolas e, sobretudo, a observação participante. Essa apropriação do instrumental antropológico de análise ocorre no momento em que ele passa por algumas transformações, impulsionadas pela urbanização e ocidentalização do objeto de investigação, uma vez que o distanciamento do universo de relações mantido pelos antropólogos foi desfeito. Como observou Montero (1993), a globalização dos padrões culturais ocidentais abalou os três pilares fundamentais sobre os quais se assentou a reflexão antropológica: “o trabal ho de campo, a interpretação do outro, a autoria" (Montero, 1993:161). A aproximação relativa do 'outro' resultou na sobreposição das técnicas de análise de discurso, para reconstrução das trajetórias individuais dos informantes, conquanto a entrevista seja seu principal material empírico, além do emprego mais sistemático de técnicas de perfil quantitativo. Os antropólogos, tradicionalmente envolvidos com o problema do recorte etnográfico, vêem-se diante da necessidade de construção de múltiplos universos de observação e da incorporação de novos horizontes conceituais, frutos da interlocução com outras disciplinas.

O deslocamento das técnicas de pesquisa ocorre em detrimento da própria observação e 
registro de atitudes, extremamente marcantes na etnografia clássica, centrais nos Estudos de Laboratório. Uma diferença entre estes estudos e a etnografia de grupos sociais urbanos é a busca, por esses últimos, de uma interação simbólica com o objeto (identificação com os valores e anseios) e os questionamentos em torno dos resultados da pesquisa para o grupo estudado (Cardoso, 1988; Durham, 1988). São questões que ocupam grande parte dos textos elaborados valendo-se da sistematização dos estudos de caso urbanos, mas que não são explicitadas pelos Estudos de Laboratório.

A utilização da observação participante como técnica de pesquisa privilegiada acentua nos Estudos de Laboratório a necessidade de registrar os papéis desempenhados pelos pesquisadores e técnicos, tipificando alguns comportamentos e confrontando-os com o discurso formulado pelos próprios atores. A análise dos discursos não pode ser descartada, contudo corremos permanentemente o risco de ficarmos reféns das explicações el aboradas pelos informantes, sem a confrontação com a trajetória de vida de cada um e a observação de suas atividades e atitudes. Identificamos nos Estudos de Laboratório um esforço para engendrar metodologias de pesquisa que recuperem o equilíbrio entre a análise de discurso, a reconstrução da história de vida e a observação participante. Afinal, o desejo de abandonar sua condição de estrangeiro, al imentado pelos pesquisadores, não implica a destituição da capacidade de surpreender-se, que fundamenta o 'olhar' antropológico sobre o outro, mesmo que este 'outro' já não seja efetivamente outro.

Os Estudos de Laboratório procuram resgatar os métodos (etnométodos) empregados pelos indivíduos (pesquisadores e técnicos) para realizarem as atividades de pesquisa no interior dos laboratórios - as escolhas, decisões, negociações, ações e sentidos -, uma vez que a inteligibilidade do processo de construção dos conhecimentos tecnocientíficos repousa na compreensão e apreensão das práticas que os constituíram. Segundo os etnometodólogos, os fatos sociais não existem enquanto realidades efetivas (que fazem sentido) quando excluídos do conjunto de práticas que os constituíram, dependendo de sua recontextualização - a referência a uma determinada situação (Coulon, 1995; Denzin, 1984). Todo o processo de legitimação (validação científica) de um enunciado, bem como seu próprio conteúdo são resultantes da articulação de um conjunto preciso de práticas - de métodos - utilizadas, compartiIhadas e constantemente atualizadas pelos atores no interior dos laboratórios. Métodos que ditam um modo particular de apreender a natureza e o universo social, de identificar e delimitar áreas problemáticas, tratando-as como objetos de pesquisa científica, de formular hipóteses explicativas, de colher e ordenar informações, e até de selecionar o que constituirá essa informação (dado), para posteriormente divulgar os resultados sob a forma de um texto científico ou protótipo. Este conjunto de práticas (de procedimentos) concedem o caráter de realidade, de cientificidade aos conhecimentos gerados nos laboratórios. O sentido destes conhecimentos está referido a uma determinada situação, ao contexto de sua produção, ao conjunto, portanto, de métodos manipulados e transformados pelos atores cotidianamente e toda sorte de situações imprevisíveis (políticas, econômicas, tecnocientíficas), extremamente contingenciais. Este contexto, por seu turno, é metamorfoseado pelos sentidos em construção no interior dos laboratórios, ou seja, pelos próprios objetos técnicos.

Os Estudos de Laboratório, portanto, não se atêm às teorias, aos mecanismos mentais do processo tecnocientífico, mas à prática em si da pesquisa: a tensão e disputa que permeiam o relacionamento entre os atores, as negociações realizadas pelos pesquisadores para assegurar o fluxo de recursos, para aprovar uma nova linha investigativa ou escrever um artigo com os últimos resultados obtidos pelo grupo. Procuram seguir os atores em seu périplo cotidiano entre os vários pólos de uma mesma rede de relações, na qual a política, a economia, os interesses de cada grupo e as controvérsias tecnocientíficas, estão mescladas; vão da bancada para a ante-sala da diretoria de alguma agência de fomento, passam pelo Congresso Nacional, expõem seus projetos em um programa de televisão, participam como cientistas/ especialistas de uma ONG.

Sendo assim, os Estudos de Laboratório distinguem-se pelas seguintes características:

a) Adotam como suposição básica que o processo de produção tecnocientífico é essencialmente contingencial;

b) o laboratório torna-se unidade mínima de análise, enquanto espaço da construção dos conhecimentos e manipulação dos etnométodos;

c) os estudos apóiam-se na microanálise das práticas tecnocientíficas (análise dos microeventos/microações que constituem aquele processo);

d) utilizam técnicas de pesquisa etnográfica para a compreensão/ apreensão dos etnométodos. 
Após a constituição deste breve painel, no qual procuramos estabelecer os contornos das proposições teórico-metodológicas da Sociologia da Ciência, e em especial dos Estudos de Laboratório, passaremos para uma nova etapa deste texto, na qual explicitaremos nossa proposta de análise do processo de trabalho dos técnicos de nível médio, em laboratórios de pesquisa e desenvolvimento da Fundação Oswaldo Cruz. Em seguida, concentrar-nos-emos nas categorias inicial mente selecionadas para efetuar esta análise.

Uma proposta de análise do trabalho técnico em laboratórios de Ciência e Tecnologia em saúde

A reconstrução das atividades realizadas cotidianamente pelos técnicos de nível médio é o eixo condutor de nosso percurso no interior dos laboratórios, atuando como via de acesso ao conjunto de problemáticas que desejamos discutir. Este acesso possibilitará a organização de informações, delineando um perfil minucioso dos técnicos, que contemple seu modo de agir e sua própria visão do mundo de trabalho no qual ele está inserido. A partir da sistematização das rotinas, pretendemos identificar e compreender: as relações técnico-pesquisador, a valorização dos técnicos como atores do processo de construção dos conhecimentos tecnocientíficos, os mecanismos para o aprimoramento profissional, as políticas de recapacitação que possi bilitam este aperfeiçoamento. A reconstrução das rotinas, aliadas à análise de discurso, tornará possível o rastreamento de expressões, valores, model os e procedimentos constituidores de um determinado campo disciplinar, com base no qual situações são solucionadas, enunciados são elaborados e comprovados. Mediante a análise do desenvolvimento do trabalho dos técnicos de nível médio, reconstruiremos uma parte do universo de relações, processos intelectuais e práticos, os quais conformam o processo de construção dos conhecimentos tecnocientíficos. Procuramos remontar mais do que o agir dos trabal hadores envolvidos na construção das tecnociências, entendendo como e por que esta ação ocorre. Reafirmamos a necessidade de compreender os fatores condicionadores da conduta dos técnicos nos laboratórios, interrogando quais fatores concedem identidade aos técnicos enquanto atores do processo de construção dos conhecimentos tecnocientíficos.

A necessidade de eleger um princípio, uma via de acesso à dinâmica interna dos laboratórios traduz igualmente o esforço para contor- nar a condição de estrangeiro, experimentada pelo pesquisador diante do universo da pesquisa, facilitando a construção de um modelo interpretativo. $\mathrm{O}$ 'ser estrangeiro' revela-se no desconhecimento das práticas, da linguagem recheada de terminologias técnicas e abreviações que as simplificam das problemáticas e categorias próprias ao campo disciplinar. Nas bancadas repletas de vidrarias, equipamentos e anotações, o pesquisador recém-chegado não encontra uma 'coerência ótica' capaz de aproximá-lo desse mundo. Este impacto diante do outro, a perda total de referências que o orientassem, foi registrada por Latour \&Woolgar (1988), ao justificarem a adoção da análise etnográfica em seu estudo do Instituto Salk. Reencontramos, ao longo da exposição, referências aos cadernos de campo, onde copilavam obsessivamente os diálogos, o desânimo frente à imbricada linguagem utilizada pelos pesquisadores e técnicos, além de um repertório de comentários, que geralmente povoam os textos etnográficos. Essa via organiza e aglutina informações, não permitindo que o pesquisador seja fagocitado pelo seu discurso articulado, perdendo-se em meio à aparente desordem imperante nos laboratórios.

“É necessário, contudo, escol her um princípi o organizador capaz del he fornecer uma visão do laboratório sufi ci entemente diversa daquela dos cientistas, mas que possa interessar tanto os biólogos, quanto os lei gos. Esse princípio organizador deve ser o fio de Ariadne que guia o observador pel o labirinto onde predomina o caos e a confusão" (Latour \& Woolgar, 1988:35).

A eleição de um princípio organizador se justifica, portanto, na necessidade dupla de engendrar um artifício para aproximar-se do outro, e concomitantemente orientar a coleta e sistematização de informações. Através desse princípio, as práticas cotidianas do laboratório e os atores em seus diferentes papéis começam a fazer sentido, permitindo a construção de modelos arquitetados pel os pesquisadores, limitados aos laboratórios estudados.

Deste modo, o ponto de partida para a execução dessa proposta é a construção de um perfil detalhado desses técnicos, observando as seguintes etapas:

a) descrição de suas atividades;

b) análise das percepções desenvolvidas pelos técnicos e pesquisadores sobre suas próprias atividades e interações;

c) identificação dos conhecimentos e habilidades, os quais constituem o saber-fazer destes técnicos;

d) os mecanismos de valorização e avaliação. 
Acreditamos que a união das proposições da Sociologia da Ciência (ou Sociologia da Inovação, ou ainda das Associações) com as análises do processo de trabalho em saúde poderão contribuir:

a) para a compreensão dos diferentes processos de trabal ho envolvidos na construção destes conhecimentos e, por conseguinte, do próprio processo de construção das tecnociências; b) com novos dados para a discussão pública das práticas tecnocientíficas;

c) para a capacitação destes profissionais, em um processo que parta do mundo do trabalho; d) para a abertura de novas perspectivas teórico-metodológicas na análise das profissões em saúde;

e) para resgatar para as discussões das profissões técnicas em saúde a dimensão material, o universo das coisas inanimadas e das teorias científicas que as cercam, constituindo seu cotidiano, mas que paradoxal mente são afastadas de debates presos somente à dimensão social.

Atores e porta-vozes e o trabalho nos laboratórios

Uma das principais características dos Estudos de Laboratório é a pouca freqüência com que seus autores se dedicaram à elaboração de trabalhos centrados na sistematização teórica de seus resultados. Invariavelmente, privilegiaram a discussão de estudos de caso, ao longo dos quais as categorias e os instrumentais metodológicos empregados são apresentados e confrontados com os resultados de análises anteriores. É possível que o maior desafio esteja no exercício de descolar estas categorias do contexto em que foram elaboradas, ou seja, das análises da construção de conhecimentos tecnocientíficos no interior de laboratórios, em um contexto específico. Manipulamos, por outro lado, um conjunto de categorias em processo de construção, alvo de um permanente exercício de desconstrução, no qual são confrontadas com diferentes realidades.

Logo, o objetivo desta etapa é explicitar as noções básicas, necessárias ao entendimento da dinâmica dos atores envolvidos no processo de construção dos conhecimentos tecnocientíficos em laboratórios de C\&T em saúde, bem como do nosso objetivo específico, qual seja, a investigação do processo de trabalho de técnicos de nível médio. Ao fazê-lo, é provável que retornemos a alguns pontos levantados anteriormente.

O laboratório é representado como um complexo campo, pelo qual se movimenta um conjunto diversificado de atores, marcados pe- la extrema variedade de interesses, visões de mundo e modos de conduta. Em um primeiro momento, discernimos neste campo relacional apenas os elementos humanos, competências (pesquisadores, técnicos, ou estagiários) reunidas em torno de algumas linhas de pesquisa. Contudo, como pensar em laboratórios e na construção e validação de fatos tecnocientíficos, sem agregar às competências uma multiplicidade de equipamentos, de substâncias químicas e cobaias? Como entender as atividades de pesquisa, sem incorporar os instrumentos de inscrição (teses, tabelas, relatórios, artigos e anotações) usados para organizar os dados, sistematizar as informações, difundir os conhecimentos produzidos no interior dos laboratórios? Didaticamente, esta rede interna pode ser segmentada em dois grandes blocos interdependentes e, na prática, indissociáveis: no primeiro, encontramos todos os atores humanos - pesquisadores, técnicos e estudantes de graduação e pós-graduação, os quais figuram como bolsistas; no outro extremo, alojamos os elementos materiais, que compõem a dimensão eminentemente técnica da pesquisa, uma série diversificada de equipamentos, substâncias químicas, textos e cobaias. Estes elementos humanos e não humanos são indistintamente identificados como atores, capazes de atrair para sua área de influência (mobilizar) entidades heterogêneas (pesquisadores, técnicos, equipamentos, artigos), constituindo redes de relações no interior dos laboratórios, para a produção de conhecimentos tecnocientíficos.

A rede de relações interna, cuja conformação delineamos sucintamente, está articulada a uma extensa associação de parceiros externos, que de algum modo participam das atividades de pesquisa, seja através de acordos de cooperação, do oferecimento de cursos, do empréstimo de equipamentos e competências. Nomeamos, com base nas sugestões de Callon (1989), este círculo de interlocutores de laboratório extenso, em oposição a rede restrita - laboratório restrito, no qual estas associações heterogêneas se traduzem em conhecimentos e artefatos tecnocientíficos ao final de um processo lento e sujeito a indeterminações de diferentes ordens.

Os conhecimentos tecnocientíficos são construídos da manipulação de uma série de mecanismos de mediação e mobilização, realizada através da operação de etnométodos, elaborados da vivência individual de cada ator no cotidiano do trabalho, onde interagem com toda sorte de elementos, e da aprendizagem e domínio de campos do conhecimento específi- 
cos das atividades do laboratório. Os ensaios práticos, que reúnem técnicos, estagiários, equipamentos e um conjunto de conhecimentos teórico-práticos, atuam na transformação do sentido construído em um contexto específico e instável em um sentido imutável, universalmente válido. Cada ensaio prático produz um sentido, um resultado, que será transformado, confirmado ou total mente abandonado, pelo posterior. O produto final é uma sucessão de sentidos, conectados entre si pela cadeia de mediações, produzidas ao longo das interações entre os diferentes atores. Cada projeto possui sua própria rede de relações no interior do laboratório, mobilizando um grupo determinado de técnicos, estagiários, pesquisadores, equipamentos, soluções, além de um certo conjunto de saberes. Deste modo, cada ator se traduz como uma microrrede de relações, articulando aliados, com o objetivo de executar e legitimar seus projetos, através da mobilização de todo tipo de elementos presentes, tanto no laboratório restrito, quanto no extenso.

Esta lista, potencialmente infinita, de elementos mobilizáveis, essenciais às atividades de pesquisa, é formada por porta-vozes (CalIon, 1989), que, ao serem envolvidos por uma determinada rede de relações, mobilizam, por sua vez, os atores humanos e não humanos representados por eles. A incorporação de um novo pesquisador pode ser traduzida como a agregação de um conjunto de competências intelectuais e saberes práticos expressos (representados) por ele, formados e apurados em uma outra instituição (laboratório extenso). Através desta capacidade de mobilizar aliados, trazendo para o interior de sua rede restrita de relações seus legítimos representantes (portavozes), os laboratórios extendem seu campo de atuação. Tornam-se, assim, capazes de mobilizar um conjunto amplo e diversificado de disciplinas. O mesmo ocorre quando pensamos nos equipamentos, um simples microscópio ótico ou um eletrônico de varredura, que expressam um conjunto de conhecimentos, de princípios científicos já validados, delimitando um certo campo de operação e aplicabilidade, representando atores invisíveis, mas mobilizáveis, graças ao ato de representação. Reencontramos este ato básico de representar al guém, junto a uma outra rede de relações, quando tratamos dos textos científicos (artigos, relatórios, comunicações apresentadas em eventos científicos), que nada mais são do que representações escritas de um experimento ou projeto em fase final de elaboração, ao lado de um campo mais dilatado de interlocutores - a comunidade científica. A representação é possi- bilitada pela capacidade de estender as redes restritas, associadas no interior dos laboratórios, para um campo mais vasto de relações, permitindo o enredamento de atores distantes, a consolidação de acordos, a negociação de intercâmbios com outros grupos.

Este exercício de mobilização de aliados por meio de porta-vozes legítimos pode ser definido como uma manipulação de feixes de força. A transformação dos diferentes elementos associados no interior dos laboratórios em feixes de força explicita-se a partir da capacidade de um ator deslocar (atrair ou repelir) aliados ou oponentes para sua área de influência, auxiliando na formação ou no fortalecimento da rede interna de relações, aumentando, assim, a capacidade de construção de conhecimentos no interior dos laboratórios. A mobilização de competências ou equipamentos pode resultar na aprovação de um projeto junto a alguma agência de fomento, ou na publicação de um artigo, em periódicos indexados. O fortalecimento da rede de relações mobilizada pelos laboratórios, ao ampliar a capacidade de construção de fatos tecnocientíficos validados pela comunidade científica internacional, fortalece, por conseguinte, o laboratório no(s) campo(s) de conhecimento no(s) qual(is) ele atua. Se consideramos que os atores, ao longo do processo de construção dos conhecimentos tecnocientíficos, mobilizam forças, podemos definir os laboratórios como associações densas de força, constituindo uma espécie de campo agonístico (Latour \& Woolgar, 1988), dentro do qual diferentes atores disputam insumos básicos para a execução de pesquisas, visando à cientifização de seus enunciados, para disputar a hegemonia de um determinado campo de conhecimento com outros laboratórios.

Os pesquisadores, enquanto chefes de núcleo, coordenadores de projetos, ou chefes do laboratório, coordenam e planejam as atividades realizadas pelo conjunto de atores, constituindo-se como feixes mais densos do campo interno de forças. Por ocuparem cargos de chefia, seja no nível departamental ou laboratorial, manipulam com mais desenvoltura os canais institucionais, intermediando, inclusive, os canais extra-institucionais. Por deterem os conhecimentos e os códigos de comunicação tecnocientíficos, terminam definindo um modo hegemônico de conduta e de expressão. Os valores próprios à carreira de pesquisa, os quais ditam a obtenção de títulos acadêmicos, publicações de artigos e intensa participação em eventos tecnocientíficos, passam a tangenciar as estratégias pessoais de atores marcados pela extrema diversidade. 
Os técnicos são atores que, mediante o domínio de procedimentos técnicos necessários à realização das etapas experimentais dos projetos, fortalecem os enunciados científicos propostos pelos pesquisadores. Para o desenvolvimento experimental dos projetos de pesquisa nas bancadas, mobilizam um amplo conjunto de atores não humanos (equipamentos, soluções, cobaias, reagentes), reunidos e transformados pelo domínio de um conjunto de conhecimentos teóricos e práticos, dos quais são porta-vozes. Associam-se, de igual modo, a inúmeros atores humanos (pesquisadores, estagiários, outros técnicos), alguns dos quais já pertencentes à rede de relações do laboratório, enquanto outros serão mobilizados através do trabalho destes técnicos, a partir de sua rede pessoal de relações no interior da instituição; asseguram a utilização das instalações laboratoriais de uma outra unidade ou laboratório, agilizando o conserto ou a instalação de algum equipamento. Neste sentido, podemos considerá-los como um ator-rede: um ator cuja ati- vidade se traduz no ato de associar uma série de elementos, canal izando os conhecimentos, as habilidades e as diferentes formas de uso de cada ponto de sua rede, para a construção de conhecimentos tecnocientíficos. Um ator, portanto, que passa a ser confundido, no interior do laboratório, com esta rede simplificada de entidades, tornando-se seu porta-voz. Deste modo, ao propormos a discussão do processo de trabalho dos técnicos, estamos nos concentrando em microrredes de relações, cujos elementos articuladores são os técnicos de nível médio. A possibilidade de compreendermos estas microrredes, sem perdermos a dimensão de totalidade dos laboratórios, é dada pela inteligibilidade das atividades realizadas nos diferentes laboratórios (suas linhas de pesquisas, projetos principais, algumas fontes de financiamento, além dos acordos de cooperação mais importantes). Este mapeamento permite a constituição de um perfil dos laboratórios, suficientemente preciso para localizarmos as atividades dos técnicos.

\section{Referências}

ALEXANDRER, J., 1987. O novo movimento teórico. Revista Brasileira deCiências Sociais, 2:5-35

BLOOR, D., 1976. Knowledgeand Social Imagery. London: Routledge and Kegan Paul.

CALLON, M., 1989. Introduction. In: La Science et ses Réseaux: Genèse et Circulation des Faits Scientifiques (M. Callon, org.), pp. 7-33, Paris: La Découverte.

CARDOSO, R., 1988. Aventura de antropólogos em campo ou como escapar das armadilhas do método. In: A Aventura Antropológica - Teoria e Pesquisa (R. Cardoso, org.), pp. 95-105. Rio de Janeiro: Paz eTerra.

COULON, A., 1995. A Etnometodologia. Rio de Janeiro: Ed. Vozes.

DENZIN, N., 1984. Interpretando as vidas de pessoas comuns: Sartre, Heidegger e Faulkner. Dados Revista de Ciências Sociais, 27:29-44.

DURHAM, E., 1988. A pesquisa antropológica com populações urbanas: problemas e perspectivas. In: A Aventura Antropológica - Teoria e Pesquisa (R. Cardoso, org.), pp. 17-37, Rio de Janeiro: Paz eTerra. GONÇALVES, R. B. M., 1994. Tecnol ogia e Organização Social das Práticas de Saúde: Características 
Tecnológicas do Processo de Trabal ho na Rede Estadual de Centros de Saúde da São Paulo. São Paulo: Hucitec. Rio de Janeiro: Abrasco.

GONÇALVES, R. B. M., 1992. A Investigação sobre Recursos Humanos em Saúde. Brasília: Ministério da Saúde (Coordenação Geral de Desenvolvimento de Recursos Humanos para o S.U.S.).

LATOUR, B., 1994. Jamais Fomos Modernos. Rio de Janeiro: Editora 34

LATOUR, B., 1989. La Science en Action. Paris: Ed. La Découverte.

LATOUR, B. \& WOOLGAR, S., 1988. La Vie de Laboratoire: La Production des Faits Scientifiques. Paris: Ed. La Découverte.

LÉVY, P., 1993. As Tecnologias da Inteligência - O Futuro do Pensamento na Era da Informática. Rio de Janeiro: Editora 34.

MERCER, H., 1985. As contribuições da sociologia à pesquisa em saúde. In: As Ciências Sociais em Saúde na América Latina (E. Nunes, org.), pp. 221-232. Brasília: OPAS.

MONTERO, P., 1993. Questões para a etnografia numa sociedade mundial. Novos Estudos Cebrap, 36:161-177.
NUNES, E., 1985a. Tendências e perspectivas das pesquisas em ciências sociais em saúde na América: uma visão geral. In: As Ciências Sociais em Saúde na América Latina: Tendências e Perspectivas ( $E$. Nunes, org.), pp. 31-71. Brasília: OPAS.

NUNES, E., 1985b. As ciências sociais nos planos de estudos de graduação e pós-graduação. In: As Ciências Sociais em Saúde na América Latina: Tendências e Perspectivas (E. Nunes, org.), pp. 427454. Brasília: OPAS.

SCHRAIBER, L., 1993. O Médico e o seu Trabalho: Limites da Liberdade. São Paulo: Hucitec.

SCHRAIBER, L. \& PEDUZZI, M., 1992. Tendências e Possibilidades da Investigação de Recursos Humanos em Saúde no Brasil. Belo Horizonte: OPS. (mimeo.)

SHAPIN, S. 1991. Le technicien Invisible. La Recherche, 230:324-334.

TEIXEIRA, M., 1994. Processo de trabalho em laboratórios: uma análise da condição dos técnicos em unidades de pesquisa da Fiocruz. Projeto Apresentado à Fundação de Amparo à Pesquisa do Estado do Rio de Janeiro (FAPERJ), Rio de Janeiro. (mimeo.) 